\title{
Pricing Strategy of Remanufacturing Closed - loop Supply Chain Based on Subsidy and Carbon Tax Mechanism
}

\author{
Wen LIU \\ Military logistics Department Logistics University of \\ People's Armed Police Force \\ Tianjin, China \\ liuwen522@126.com
}

Long-gang LI*

Military logistics Department Logistics University of People’s Armed Police Force

Tianjin, China

772758547 @qq.com

\author{
Hai-yan WANG \\ Military logistics Department Logistics University of \\ Tianjin Public Vocational Training Center of China \\ Tianjin, China \\ wanghaiyan_hellen@163.com
}

\author{
Jie DENG \\ Military logistics Department Logistics University of \\ People's Armed Police Force \\ Tianjin, China \\ dj.love.1987@163.com
}

\begin{abstract}
Under the government subsidy and carbon tax mechanism, a game-pricing model of government and closedloop supply chain members is established for closed-loop supply chain system consisting of manufacturers, retailers and third parties. The optimal subsidy intensity and carbon tax rate are obtained by the maximum social welfare. Then, the impact of the proportion of waste materials on the subsidy intensity and carbon tax rate, recycling strategy of waste products and the profit of remanufacturing closed-loop supply chain members is analyzed by numerical simulation. The study shows that the government adopts a low subsidy and low carbon tax strategy for the raw materials, and adopts a higher subsidy and a higher carbon tax policy for the discarded goods in the component level, and adopts a high subsidy and high carbon tax strategy for the product scrap. Therefore, the recycling prices of waste products, recovery efforts with the decline in the quality of waste products are increased. Product wholesale prices and retail prices are rising with the rise in product quality.
\end{abstract}

Keywords-component; closed-loop supply chain; stackelberg game; prive strategy; subsidy mechanism; carbon tax mechanism

\section{INTRODUCTION}

In recent years, with the rapid development of science and technology, the upgrading of electronic products is becoming more and more frequent. The economic value and environmental protection of recycling and recycling of waste products have been widely recognized. In 2012, China implemented the "Waste Electrical and Electronic Products Processing Fund Collection and Subsidy Management Approach", provides for regular waste electrical recycling enterprises to give each 35 to 85 RMB subsidy. However, due to the remanufacturing technology of China's electronics industry is not very mature and the very original means of treatment liquid directly into the surrounding environment, has caused serious ecological consequences. Therefore, in addition to subsidies for the electronic product remanufacturing process, the government should impose a carbon tax to control its carbon emissions. Based on this, how to coordinate the subsidy and the carbon tax mechanism to achieve both incentives to remanufacture and reduce the remanufacturing process of carbon emissions purposes, and the pricing decisions based on subsidies and how to make carbon tax mechanism will be the focus of this study.

At present, many scholars have studied the pricing strategy of waste materials recycling, the literature studied the recovery of waste products under the uncertain quality of the optimal pricing strategy and recovery $[1,2,3]$. The literature based on new products and remanufactured products non-discriminatory pricing, demand and the amount of recovery under the uncertainty of the pricing strategy $[4,5,6]$. The game model of waste product recycling price is established, and the influence of system parameters on the pricing decision of closed-loop supply chain members is analyzed $[7,8]$. In relation to the CLSC pricing strategy study involving government participation, Scott Webster and Supriya Mitra studied the impact of government subsidies on remanufacturing activities $[9,10]$. The literature analyzes the impact of government subsidies and environmental laws on the pricing of CLSC members [11,12,13,14]. Rui Zhao used the game theory to consider the environmental risk and the manufacturer's decision under carbon emission [15]. JB. Sheu analyzed the impact of government financial subsidies on the coordination and cooperation of reverse supply chain members and green supply chain competition $[16,17]$.

In summary, this paper takes the electronic remanufacturing enterprises as the research background, based on the policy of combining government subsidy with carbon tax, considering the different forms of reuse of waste products, establishing a two-stage game model between government and CLSC members, how the government sets up a subsidy and carbon tax mechanism, and remanufacturing pricing strategies for members of the CLSC under the mechanism. 


\section{The Model Description AND BASIC AsSUMPTIONS}

\section{A. Description of the Problem}

Assuming that the government has a subsidy and carbon tax mechanism to remanufacture CLSC members, the manufacturer is responsible for the entire production process of raw materials, parts and components and final products. The waste products are reclaimed by third parties, tested and classified, and recycled products are reused characteristics of dismantling into three level. The remanufactured CLSC structure thus constructed is shown in Fig.1.

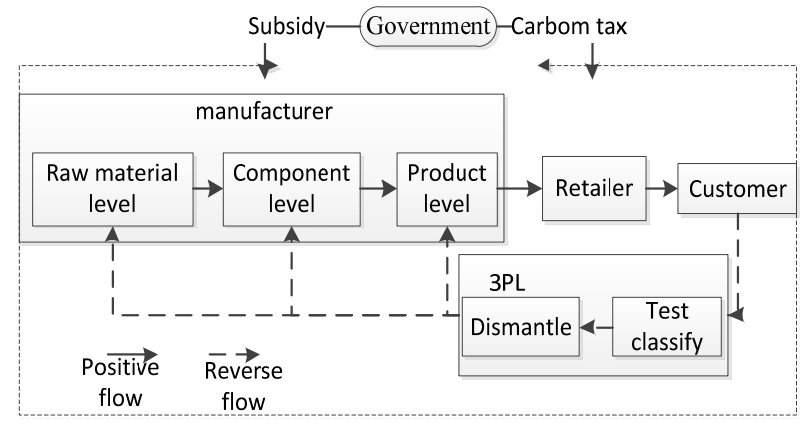

Figure 1. Remanufacturing the CLSC structure.

\section{B. The Symbolic Agreement}

$\varphi$ : Reuse of waste materials at different levels, product layer. $c_{\varphi}$ : Unit level $\varphi$ of the waste product remanufacturing unit costs of which $c_{1}>c_{2}>c_{3} . \Delta_{\varphi}$ : The marginal cost of remanufacturing of waste products at the unit level $\varphi$, and $\Delta_{1}<\Delta_{2}<\Delta_{3} \cdot l_{\varphi}$ : Unit level of waste products accounted for the proportion of waste products, of which $l_{1}+l_{2}+l_{3}=1$. $p_{\varphi}$ : Respectively, for new products, remanufactured products, second-hand products, the unit retail price. $\omega_{\varphi}$ : Respectively, for new products, remanufactured products, second-hand products, the wholesale price of the unit. $r_{\varphi}$ : The manufacturers buy back the purchase price of the scrap at the unit level from the third party. To simplify the model, suppose $r_{2}=h r_{1}, r_{3}=k r_{1}$ that is constant. $D_{\varphi}=a_{\varphi}-b_{\varphi} p_{\varphi}$ : The demand function of new product, remanufactured product and used product respectively, where $a_{\varphi}, b_{\varphi}$ is a constant greater than 0 , which $a_{\varphi}$ indicates the market potential demand of the corresponding product, and $b_{\varphi}$ indicates the sensitivity coefficient of the consumer to the selling price of the corresponding product. $f$ : The price of waste recycling unit, for third-party decision-making variables. $e$ : Third-party recovery efforts. $S_{\varphi}$ : Government subsidies for the unit level $\varphi$ to give third-party efforts. Likewise, to simplify the model, it is assumed $s_{2}=v s_{1}, s_{3}=\eta s_{1}$ that $\mu, \eta$ is constant. $E_{\varphi \vartheta}$ : The carbon emissions of waste products $\varphi$ in the process of remanufacturing $\vartheta, \vartheta=1,2$ including the dismantling process and the remanufacturing process. $t$ : The carbon tax rate, that is, the carbon tax per unit of carbon emissions. The carbon emissions $E_{t \phi}$ from the consumer to the third party $E_{t 1}$, from the third party to the manufacturer $E_{t 1}$, and from the manufacturer to the retailer $E_{t 3} \cdot R=\alpha+\beta f+\lambda e$ : Recycling amount of waste products, which $\alpha, \beta, \lambda$ is a constant greater than 0 , which $\alpha$ indicates that when the recovery of prices and efforts to zero the amount of waste supply, indicating that some consumers are willing to return the amount of waste free of charge, $\beta, \lambda$ reflecting the consumer awareness of environmental protection. Further, this article is used $\pi_{i}$ to represent the profits of CLSC's member $i$ which is $M, R, 3 P$, and, respectively, said manufacturers, retailers, third parties.

\section{The Basic Model}

Hypothesis 1: The manufacturer uses the raw material waste to remanufacture as the new product. Correspondingly, the spare parts of the parts layer are remanufactured as remanufacturing, and the product layer of the used product is remanufactured as second-hand product. These three kinds of products demand mutual independent and non-consumer transfer.

Hypothesis 2: The market is fully opened, the CLSC members are made in the case of information symmetry decision-making. The market demand for the product is relatively stable, the situation is similar to each cycle. So this paper only study single cycle.

\section{MOdEL Establishment AND SOLUTION}

Based on the game between government and enterprise in remanufacturing CLSC, a two-stage model is established. (1) Through the social welfare maximization $[16,17]$, we get the best government subsidies and carbon tax rate.(2) Given $s_{\varphi}^{*}$ and $t^{*}$, remanufacturing CLSC members to formulate optimal pricing strategies. In this paper, the reverse induction method is used to solve the model, that is, to solve the optimal solution of the second stage, and then find the equilibrium solution of the government in the first stage.

\section{A. Remanufacturing CLSC Members Optimal Pricing Decision}

Given the government subsidy $s_{\varphi}$ and the carbon tax rate, the manufacturer determines the wholesale price $\omega_{\varphi}$ and repurchase price $r_{\varphi}$ for the Stackelberg leader, the retailer sets the optimal retail price $p_{\varphi}$ for the given wholesale price, and the third party recycler decides The optimal recovery price $f$ and recovery efforts $e$. The solution can be seen as a 
simultaneous action game. According to the background of the model, we get the profit function:

$$
\begin{gathered}
\pi_{M}=\sum_{\varphi=1}^{3}\left(\omega_{\varphi}-c_{\varphi}-E_{\varphi 2} t-E_{t 3} t\right) D_{\varphi}+\left(\sum_{\varphi=1}^{3} \Delta_{\varphi} l_{\varphi}\right) R-\sum_{\varphi=1}^{3} l_{\varphi} R r_{\varphi} \\
\pi_{R}=\sum_{\varphi=1}^{3}\left(p_{\varphi}-\omega_{\varphi}\right) D_{\varphi} \\
\pi_{3 P}=\sum_{\varphi=1}^{3}\left(l_{\varphi} r_{\varphi}+l_{\varphi} s_{\varphi}\right) R-f R-\frac{1}{2} c_{3 P} e^{2}-\left[\sum_{\varphi=1}^{3}\left(E_{\varphi 1} l_{\varphi}\right)+\sum_{\phi=1}^{2} E_{t \phi}\right] R t
\end{gathered}
$$

According to the reverse derivation method, the optimal retail price of the retailer $p_{\varphi}^{*}$, the optimal recovery price of the third party $f^{*}$ and the optimal recovery effort $e^{*}$ are determined first. For the given $\omega_{\varphi}$ as second derivative $\frac{\partial^{2} \pi_{R}}{\partial p_{\varphi}{ }^{2}}=-2 b_{\varphi}<0, \pi_{R}$ is strictly convex function(2) on $p_{\varphi}$. There is the optimal solution of function(2).The optimal response function on

$$
\omega_{\varphi}: p_{\varphi}=\frac{\omega_{\varphi}}{2}+\frac{a_{\varphi}}{2 b_{\varphi}}
$$

For the given $\omega_{\varphi}$ and $r_{\varphi}$ the second derivatives of (3) on $f$ is $\frac{\partial^{2} \pi_{3 P}}{\partial f^{2}}=-2 \beta<0$ and the second derivatives of (3) on $e$ is $\frac{\partial^{2} \pi_{3 P}}{\partial e^{2}}=-c_{3 P}<0, \pi_{3 p}$ is joint concave function on $f$ and $e$. There is the optimal solution of (3). The optimal response function on $\omega_{\varphi}$ and $r_{\varphi}$ is:

$$
\begin{gathered}
f=\frac{\left[\sum_{\varphi=1}^{3}\left(l_{\varphi} r_{\varphi}+l_{\varphi} s_{\varphi}\right)-\left(\sum_{\varphi=1}^{3} E_{\varphi 1} l_{\varphi}+\sum_{\phi=1}^{2} E_{t \phi}\right) t\right]\left(c_{3 P} \beta-\lambda^{2}\right)-c_{3 P} \alpha}{2 c_{3 P} \beta-\lambda^{2}} \\
e=\frac{\lambda\left[\sum_{\varphi=1}^{3}\left(l_{\varphi} r_{\varphi}+l_{\varphi} S_{\varphi}\right) \beta+\alpha-\left(\sum_{\varphi=1}^{3} E_{\varphi 1} l_{\varphi}+\sum_{\phi=1}^{2} E_{t \phi}\right) t \beta\right]}{2 c_{3 P} \beta-\lambda^{2}}
\end{gathered}
$$

And then determine the manufacturer's optimal wholesale price $\omega_{\varphi}^{*}$, the optimal repurchase price $r_{\varphi}^{*}$. Substituting (4)

(6) into (1), since $r_{2}=h r_{1}, r_{3}=k r_{1}$, therefore, only the second derivative $\pi_{M}$ on $\omega_{\varphi}$ and $r_{1}$ is required. We get second derivative function $\frac{\partial^{2} \pi_{M}}{\partial r_{1}^{2}}=\frac{2 c_{3 P} \beta^{2}\left(l_{1}+h l_{2}+k l_{3}\right)}{\lambda^{2}-2 c_{3 P} \beta}$ and $\frac{\partial^{2} \pi_{M}}{\partial \omega_{\phi}{ }^{2}}=-b_{\phi}<0$. Obviously, when $\lambda^{2}-2 c_{3 P} \beta<0, \pi_{M}$ is the joint concave function on $\omega_{\varphi}$ and $r_{1}$. There is the optimal solution of (1) which can be obtained by the manufacturer's optimal wholesale price $\omega_{\varphi}^{*}$ and the optimal repurchase

$$
\text { price. } r_{\varphi}^{*}: \omega_{1}^{*}=\frac{c_{1}}{2}+\frac{a_{1}}{2 b_{1}}+\frac{E_{12}+E_{t 3}}{2} t
$$

$$
\begin{gathered}
\omega_{2}^{*}=\frac{c_{2}}{2}+\frac{a_{2}}{2 b_{2}}+\frac{E_{22}+E_{t 3}}{2} t, \omega_{3}^{*}=\frac{c_{3}}{2}+\frac{a_{3}}{2 b_{3}}+\frac{E_{32}+E_{t 3}}{2} t \\
r_{1}^{*}=\frac{\left[\left(\sum_{\varphi=1}^{3} E_{\varphi 1} l_{\varphi}+\sum_{\phi=1}^{2} E_{t \phi}\right) t+\sum_{\varphi=1}^{3} l_{\varphi} \Delta_{\varphi}-\left(l_{1}+l_{2}+\eta l_{3}\right) s_{1}\right] \beta-\alpha}{2 \beta\left(l_{1}+h l_{2}+k l_{3}\right)}
\end{gathered}
$$

$$
r_{2}^{*}=h \frac{\left[\left(\sum_{\varphi=1}^{3} E_{\varphi 1} l_{\varphi}+\sum_{\phi=1}^{2} E_{t \phi}\right) t+\sum_{\varphi=1}^{3} l_{\varphi} \Delta_{\varphi}-\left(l_{1}+v l_{2}+\eta l_{3}\right) s_{1}\right] \beta-\alpha}{2 \beta\left(l_{1}+h l_{2}+k l_{3}\right)}
$$

$$
r_{3}^{*}=k \frac{\left[\left(\sum_{\varphi=1}^{3} E_{\varphi 1} l_{\varphi}+\sum_{\phi=1}^{2} E_{t \phi}\right) t+\sum_{\varphi=1}^{3} l_{\varphi} \Delta_{\varphi}-\left(l_{1}+v l_{2}+\eta l_{3}\right) s_{1}\right] \beta-\alpha}{2 \beta\left(l_{1}+h l_{2}+k l_{3}\right)}
$$

Substituting (7) (9) into (4), the optimal retail price of retailer is(13) (15) below:

$p_{1}^{*}=\frac{c_{1}}{4}+\frac{3 a_{1}}{4 b_{1}}+\frac{E_{12}+E_{t 3}}{4} t p_{2}^{*}=\frac{c_{2}}{4}+\frac{3 a_{2}}{4 b_{2}}+\frac{E_{22}+E_{t 3}}{4} t \quad p_{3}^{*}=\frac{c_{3}}{4}+\frac{3 a_{3}}{4 b_{3}}+\frac{E_{32}+E_{t 3}}{4} t$

Substituting (13) (15) into the demand function, the formulas $(16) \sim(17)$ are substituted into the reclaim function.

$f^{*}=\frac{\left[s_{1}\left(l_{1}+\mathcal{U}_{2}+\eta l_{3}\right)+\sum_{\varphi=1}^{3} l_{\varphi} \Delta_{\varphi}-\left(\sum_{\varphi=1}^{3} E_{\varphi 1} l_{\varphi}+\sum_{\phi=1}^{2} E_{t \phi}\right) t\right] \beta\left(c_{3 P} \beta-\lambda^{2}\right)-\alpha\left(3 c_{3 P} \beta-\lambda^{2}\right)}{2 \beta\left(2 c_{3 P} \beta-\lambda^{2}\right)}$

$$
e^{*}=\frac{\lambda\left\{\left[\sum_{\varphi=1}^{3} l_{\varphi} \Delta_{\varphi}+\left(l_{1}+v l_{2}+\eta l_{3}\right) s_{1}-\left(\sum_{\varphi=1}^{3} E_{\varphi 1} l_{\varphi}+\sum_{\phi=1}^{2} E_{t \phi}\right) t\right] \beta+\alpha\right\}}{2\left(2 c_{3 P} \beta-\lambda^{2}\right)}
$$

$$
D_{1}^{*}=\frac{a_{1}}{4}-\frac{b_{1} c_{1}}{4}-\frac{b_{1}\left(E_{12}+E_{t 3}\right)}{4} t
$$




$$
\begin{gathered}
D_{2}^{*}=\frac{a_{2}}{4}-\frac{b_{2} c_{2}}{4}-\frac{b_{2}\left(E_{22}+E_{t 3}\right)}{4} t \\
D_{3}^{*}=\frac{a_{3}}{4}-\frac{b_{3} c_{3}}{4}-\frac{b_{3}\left(E_{32}+E_{t 3}\right)}{4} t \\
R^{*}=\frac{c_{3 P} \beta\left[\left(\sum_{\varphi=1}^{3} l_{\varphi} \Delta_{\varphi}+\left(l_{1}+v_{2}+\eta l_{3}\right) s_{1}\right) \beta+\alpha-\left(\sum_{\phi=1}^{3} E_{\varphi 1} l_{\varphi}+\sum_{\phi=1}^{2} E_{t \phi}\right) t \beta\right]}{2\left(2 c_{3 P} \beta-\lambda^{2}\right)}
\end{gathered}
$$

From $(7) \sim(21)$, the expected profits of the manufacturer, the retailer and the third party are:

$$
\begin{gathered}
\pi_{R}^{*}=\sum_{\varphi=1}^{3} \frac{\left[b_{\varphi} c_{\varphi}-a_{\varphi}+\left(E_{\varphi 2}+E_{t 3}\right) b_{\varphi} t\right]^{2}}{16 b_{\varphi}} \\
\pi_{M}^{*}=\sum_{\phi=1}^{3} \frac{\left[b_{\phi} c_{\phi}-a_{\phi}+\left(E_{\phi 2}+E_{t 3}\right) b_{\phi} t\right]^{2}}{8 b_{\phi}}+ \\
\frac{c_{3 P}\left[\left(\sum_{\phi=1}^{3} l_{\phi} \Delta_{\phi}+\left(l_{1}+v l_{2}+\eta l_{3}\right) s_{1}\right) \beta-\left(\sum_{\phi=1}^{3} E_{\phi 1} l_{\phi}+\sum_{\varphi=1}^{2} E_{t \varphi}\right) t \beta+\alpha\right]^{2}}{4\left(2 c_{3 P} \beta-\lambda^{2}\right)} \\
\pi_{3 P}^{*}=\frac{c_{3 P}\left\{\left[\sum_{\varphi=1}^{3} l_{\varphi} \Delta_{\varphi}+\left(l_{1}+v l_{2}+\eta l_{3}\right) s_{1}\right] \beta-\left(\sum_{\phi=1}^{3} E_{\varphi 1} l_{\varphi}+\sum_{\phi=1}^{2} E_{t \phi}\right) t \beta+\alpha\right\}^{2}}{8\left(2 c_{3 P} \beta-\lambda^{2}\right)}
\end{gathered}
$$

The wholesale price, retail price and demand for new products, remanufactured products and second-hand products are determined by the government's carbon tax for the remanufacturing and transportation process and the manufacturers' own remanufacturing costs. Government subsidies have nothing to do. As these three types of products are made of raw materials, components, product layer of waste products remanufactured, so remanufacturing costs and processes, respectively, with the quality of discarded products decreased the quality of the declining trend. These three types of products wholesale prices and retail prices were gradually decreased. For consumers, the psychological expectations of these three types of products prices also showed a downward trend, therefore, this pricing method is more realistic. However, with the carbon tax rate increases, the three types of products, wholesale prices and retail prices will increase, demand will decline. Based on this, the government develops carbon tax mechanism, the products should be considered different carbon emissions and tax rate, guiding and controlling the use of recycled waste materials at all levels to carry out the remanufacturing. For enterprises, should be in the existing based on the process adjustment, equipment improvement, technology upgrading, thus reducing the three types of products, the energy consumption of the unit remanufacturing process, thereby reducing its carbon emissions.

\section{B. The Optimal Government Subsidies and Carbon Tax Policy}

Suppose the objective function SW mainly includes five elements: (1) consumer surplus; (2) producer (including manufacturers, retailers and third parties; (3) government revenue and expenditure; (4) environmental benefits from resource recycling; (5) environmental costs due to product production. Then the objective function can be expressed as:

$$
\begin{array}{r}
S W=C S+P S+E I+E B-E C=\sum_{\phi=1}^{3} \frac{1}{2} b_{\phi} D_{\phi}^{* 2}+\left(\pi_{M}^{*}+\pi_{R}^{*}+\pi_{3 P}^{*}\right)+ \\
\sum_{\phi=1}^{3} J_{\phi} l_{\phi} R^{*}+\left\{t\left(\sum_{\vartheta=1}^{2} \sum_{\phi=1}^{3} E_{\phi \vartheta}+\sum_{\varphi=1}^{3} E_{t \varphi}\right)-\sum_{\phi=1}^{3} l_{\phi} s_{\phi} R^{*}\right\}-\sum_{\phi=1}^{3} K_{\phi} D_{\phi}^{*}
\end{array}
$$

The environmental benefit output per unit processed product $J_{\varphi}$ obtained from the third-party processing grade $\varphi$ waste product. $K_{\varphi}$ indicates the environmental treatment cost per unit product produced by the manufacturer using the grade $\varphi$ discarded product.

To simplify the model, we assume that $s_{2}=v s_{1}, s_{3}=\eta s_{1}$ for the given $D_{\varphi}^{*}, R^{*}, \pi_{M}^{*}, \pi_{R}^{*}, \pi_{3 P}^{*}$, according to Hessian matrix about $S W$ on $s_{1}$ and $t$. There is the optimal solution of it.

The optimal equilibrium solution $s_{1}^{*}$ and $t^{*}$ substitution into the first stage can determine the optimal decision $\omega_{\varphi}^{*}, p_{\varphi}^{*}, e^{*}, f^{*}$ and the optimal profit $\pi_{M}^{*}, \pi_{R}^{*}, \pi_{3 P}^{*}$ of the remanufacturing CLSC members. Due to the length of the relationship, here is no longer open statement.

$$
\begin{aligned}
& \left(2 c_{3 P} \beta-\lambda^{2}\right)\left[\begin{array}{l}
\sum_{\phi=1}^{3}\left(E_{\phi 2}+E_{t 3}\right)\left(a_{\phi} b_{\phi}^{2}-b_{\phi}^{3} c_{\phi}-4 K_{\phi} b_{\phi}+6 a_{\phi}-6 b_{\phi} c_{\phi}\right)- \\
\left(16 \sum_{g=1}^{2} \sum_{\phi=1}^{3} E_{\phi,}+16 \sum_{\phi=1}^{3} E_{t \varphi}\right)
\end{array}\right] \\
& t^{*}=\frac{+16 c_{3 P} \alpha \beta\left(\sum_{\phi=1}^{2} E_{t \varphi}+\sum_{\phi=1}^{3} E_{\phi 1} 1_{\phi}\right)\left\{\alpha+\beta \sum_{\phi=1}^{3} l_{\phi}\left(J_{\phi}+\Delta_{\phi}\right)\right\}}{16 c_{\beta}\left(\beta^{2}\left(E^{2} l_{\phi}+\sum^{2} E^{2}\right)+\right.} \\
& 16 c_{3 P} \beta^{2}\left(\sum_{\phi=1}^{3} E_{\phi 1}^{2} l_{\phi}^{2}+\sum_{\varphi=1}^{2} E_{t \varphi}^{2}\right)+ \\
& 32 c_{3 P} \beta^{2}\left(E_{11} l_{1} \sum_{\phi=2}^{3} E_{\phi 1} l_{\phi}+E_{21} E_{31} l_{2} l_{3}+E_{t 1} E_{t 2}+\sum_{\phi=1}^{3} E_{\phi 1} l_{\phi} \sum_{\varphi=1}^{2} E_{t \varphi}\right) \\
& +\left[\begin{array}{l}
2 E_{t 3}\left(\sum_{\phi=1}^{3} E_{\phi 2} b_{\phi}^{3}+6 \sum_{\phi=1}^{3} E_{\phi 2} b_{\phi}\right)+ \\
\left(\sum_{\phi=1}^{3} E_{\phi 2}^{2} b_{\phi}^{3}+6 \sum_{\phi=1}^{3} E_{\phi 2}^{2} b_{\phi}\right)+ \\
E_{t 3}^{2}\left(\sum_{\phi=1}^{3} b_{\phi}^{3}+6 \sum_{\phi=1}^{3} b_{\phi}\right)
\end{array}\right]\left(2 c_{3 P} \beta-\lambda^{2}\right) \\
& s_{1}^{*}=\frac{\beta \sum_{\varphi=1}^{3} l_{\varphi} \Delta_{\varphi}+2 \beta \sum_{\varphi=1}^{3} J_{\varphi} l_{\varphi}-\alpha}{\beta\left(l_{1}+v l_{2}+\eta l_{3}\right)}-\frac{\sum_{\varphi=1}^{3} E_{\varphi 1} l_{\varphi}+\sum_{\phi=1}^{3} E_{t \phi}}{\left(l_{1}+v l_{2}+\eta l_{3}\right)} t^{*}
\end{aligned}
$$




\section{NUMERICAL ANALYSIS}

Section 2 solves the optimal decision of remanufacturing CLSC members under subsidy and carbon taxation mechanism by establishing a two-stage programming model of government and remanufacturing CLSC members. In view of the complexity of partial solution, the paper analyzes the impact of the proportion of waste products at different levels on government subsidy and carbon tax mechanism, third party reclamation strategy and recycling volume, CLSC member profit based on the conclusions drawn in Section 2, using numerical analysis. An electronic enterprise related parameters are as follows: $c_{1}=100, c_{2}=80, c_{3}=60$, $\Delta_{1}=20, \Delta_{2}=40, \Delta_{3}=60, a_{1}=3000, b_{1}=10$, $a_{2}=4000, b_{2}=20, a_{3}=3000, b_{3}=25, \alpha=2, \beta=5$, $\lambda=10, \quad c_{3 P}=25, \quad E_{11}=8, \quad E_{21}=5, \quad E_{31}=3, E_{t 1}=2$, $E_{t 2}=1, E_{t 3}=3, E_{12}=6, E_{22}=4, E_{32}=2, J_{1}=100$, $J_{2}=150, J_{3}=200, K_{1}=100, K_{2}=80, K_{3}=60, l_{1}=0.2$, $l_{2}=0.5, l_{3}=0.3, h=5, k=8, v=0.6, \eta=0.4$. First of all, the proportion of waste at all levels of government subsidies and the impact of carbon tax mechanism, so the above data into (26) (27) available:

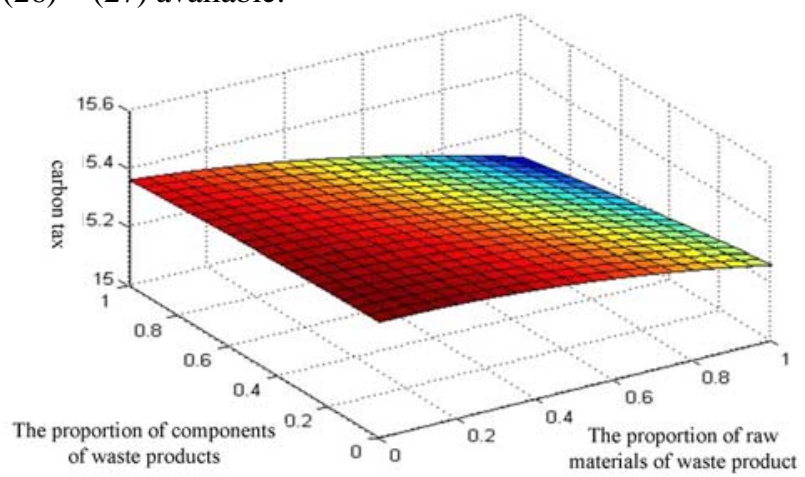

Figure 2. The trend of carbon tax rate with the proportion of each layer of waste products

As can be seen from Fig.2, with the proportion of raw materials, waste parts, parts of the increase in the proportion of waste products, carbon tax rates are reduced. We get $t^{*}=15.26$ when $\left(l_{1}, l_{2}\right)=(1,0)$. Third-party recycling of waste products in the form of raw materials to remanufacture, the optimal carbon tax rate is 15.26 . We get $t^{*}=15.36$ when $\left(l_{1}, l_{2}\right)=(0,1)$. At that time, third-party recycling of all the waste products in the form of remanufacturing parts, the optimal carbon Tax rate of 15.36 . We get $t^{*}=15.40$ when $\left(l_{1}, l_{2}\right)=(0,0)$. When the recycling of third-party recycling of all products in the form of remanufacturing, the optimal carbon tax rate of 15.40 . This is because the product layer of waste products in the whole process of remanufacturing carbon emissions is low, lower requirements for remanufacturing technology, enterprises to obtain higher profits, so the third party is more willing to recover the product layer of waste products. The government developed a higher carbon tax rate. For the raw material layer of waste materials remanufacturing process of high carbon emissions, the government to develop a lower carbon tax rate to guide enterprises to effectively remanufacture.

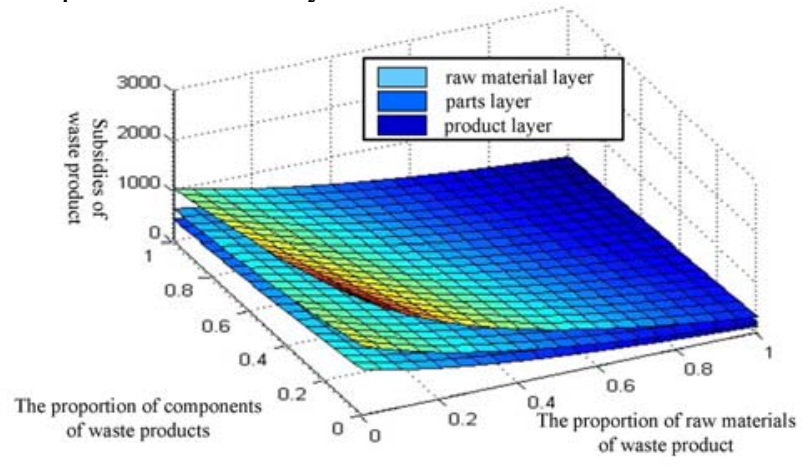

Figure 3. The intensity of the subsidy of waste materials with the proportion of each layer of waste products trends

Can be seen from Fig.3, with the proportion of raw materials, waste materials, parts of the proportion of waste products increased, the intensity of subsidies for all levels of waste products are reduced. We get $s_{1}^{*}=305.96$ when $\left(l_{1}, l_{2}\right)=(1,0)$.At that time, third-party recycling of waste products in the form of raw materials to remanufacturing, raw material layer of the optimal subsidy of 305.96.We get $s_{2}^{*}=620.64$ when $\left(l_{1}, l_{2}\right)=(0,1)$. At this time the third-party recycling of all the waste products in the form of remanufacturing parts, and the subsidy intensity is 620.64. We get $s_{3}^{*}=921$ when $\left(l_{1}, l_{2}\right)=(0,0)$.At that time, the thirdparty recycling of all the waste products in the form of product remanufacturing, product layer optimal subsidy is 921. This is because the government for the raw material layer of waste products levied a lower carbon tax, product level waste products for higher carbon tax, so in order to effectively guide enterprises to use various levels of waste recycling and remanufacturing. The government developed a lower raw material level waste subsidy efforts, a higher product layer of waste products to subsidize efforts.

TABLE I. THE OPTIMAL SUBSIDY INTENSITY AND OPTIMAL CARBON TAX RATE FOR WASTE MATERIALS IN EACH LAYER

\begin{tabular}{|c|l|l|l|}
\hline Layer of waste & $\begin{array}{c}\text { raw materials } \\
\text { layer }\end{array}$ & $\begin{array}{c}\text { raw materials } \\
\text { layer }\end{array}$ & product layer \\
\hline Tax rate & 305.96 & 620.64 & 921 \\
\hline Carbon tax & 15.26 & 15.36 & 15.40 \\
\hline
\end{tabular}

In summary, the table 1 , due to the cost of remanufacturing process of waste materials and carbon emissions at different levels, so the government for the raw material layer of waste products to take low subsidies, low carbon tax strategy for the parts of the waste high subsidies, a higher carbon tax strategy, the product layer of waste products to take high subsidies, high carbon tax strategy. This led the remanufacturing enterprises to actively recycle used products, and invested heavily in dismantling processing equipment and remanufacturing technology to reduce carbon emissions from the recycling and remanufacturing processes. 
Then, we study the influence of the proportion of used products at different levels on the third-party pricing decision and CLSC profit. Therefore, the relevant parameters of the electronic enterprise can be brought into (14) (15) and (21) $\sim$ (24). The following results were obtained.

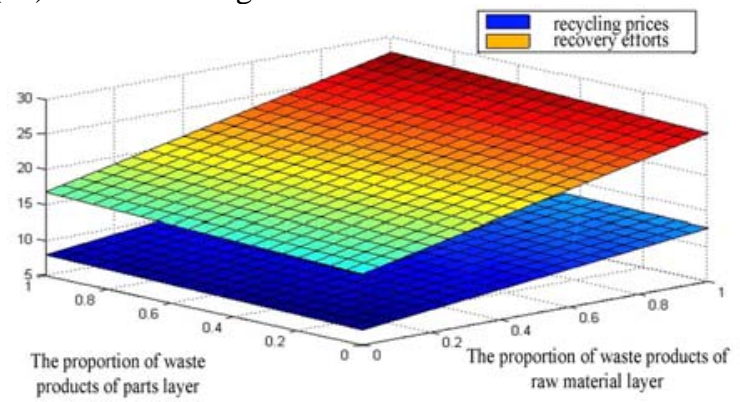

Figure 4. Scrap recycling prices and recovery efforts with the level of the proportion of waste materials trends

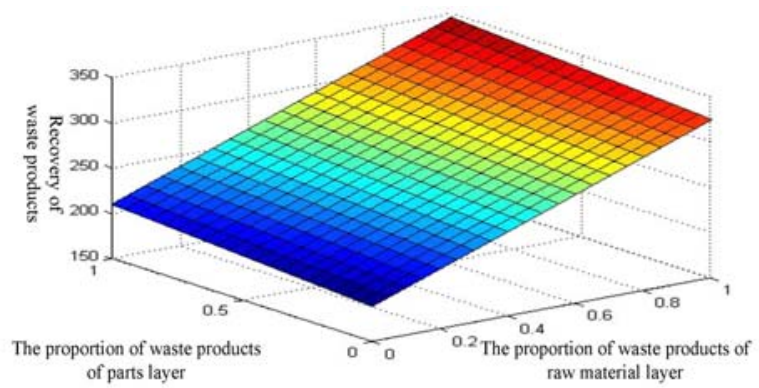

Figure 5. Recycling of waste products with the proportion of the level of waste materials trends

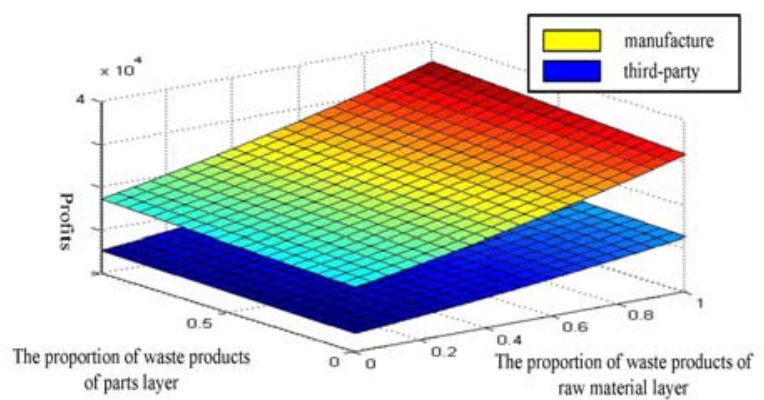

Figure 6. Manufacturers and third-party profits with the proportion of the trend of waste

It can be seen from Fig.4 and Fig.5, with the proportion of raw materials, waste parts, parts of the increase in the proportion of discarded products, recycling prices of waste products, recovery efforts have increased, so the recovery of waste materials with the raw material layer waste the proportion of parts, parts of the proportion of waste products increased. This is because when the waste materials into raw materials in the form of remanufacturing link, the whole remanufacturing process of carbon emissions is relatively high, the government in order to guide enterprises to recover, a lower carbon tax, while the third party also received a corresponding subsidy and third parties benefit from this so the higher the recycling price and the higher recycling effort, the better the recovery high. When the waste products in the form of parts or products into the remanufacturing, the entire remanufacturing process of carbon emissions is relatively low, the government imposed a higher carbon tax, the thirdparty advanced environmentally friendly dismantling equipment, less investment. As can be seen from Fig.6, with the proportion of raw materials, waste parts, parts of the proportion of waste products increased, manufacturers and third-party profits are rising. This is because the cost of remanufacturing is high and the carbon emission is high when the waste products are tested and dismantled into raw material layers. While improving the quality of low-quality waste products are not a good recycling phenomenon, manufacturers and third parties get benefits. When the waste products dismantle into parts or product layer, the government take a high subsidy, high carbon tax strategy to guide enterprises not only use good quality waste remanufacturing, but take more attention to those poor quality of waste products in order to achieve low carbon remanufacture mode.

\section{CONCLUDING REMARKS}

This paper establishes the two-stage game pricing model of government and remanufacturing CLSC system, and obtains the optimal subsidy intensity and the optimal carbon tax rate with the goal of social welfare maximization. This paper analyzes the impact of different level of waste products on the subsidy intensity and carbon tax rate, recovery price of waste products, recovery efforts, recycling amount and profit of remanufacturing CLSC members, and obtains the following results:

1) The government adopts a low subsidy and low carbon taxation strategy for the raw materials and waste materials; adopts a high subsidy and a high carbon tax policy for the discarded goods in the component level; and adopts a high subsidy and high carbon tax strategy for the waste products in the product layer.

2) Recycling prices of raw and processed materials > recycling prices of parts and materials used for recycling $>$ recycling prices of waste materials at the product level; recycling efforts of raw materials and waste materials> product layer waste product recycling efforts; raw material layer of waste products repurchase prices $>$ parts layer of waste products repurchase prices $>$ product layer of waste products repurchase price.

3) The wholesale price and retail price of the three kinds of products increase with the increase of the carbon tax rate, but they are not affected by the subsidy intensity; and the wholesale price of the new product $>$ the remittance price of the second-hand product; retail prices $>$ retail prices of remanufactured products $>$ retail prices of used products.

With the popularization of e-business, considering the impact of traditional recycling and e-recycling on CLSC pricing strategy will be the main direction of further research. 


\section{ACKNOWLEDGMENT}

The authors wish to thank Logistics University of People’s Armed Police Force, Tianjin University.

\section{REFERENCES}

[1] Savaskan R C, Wassenhove L V, "Reverse channel design: The case of competing retailers,” Mangement Science, vol. 52, Jan. 2006, pp. 1-14, doi:10.1287/mnsc.1050.0454.

[2] Shaligram P, Yijiong L, “A model to evaluate acquisition price and quantity of used products for remanufacturing,”International Journa of Production Economics, vo;. 138, Jul. 2012, pp. 170-176, doi:10.1016/j.jipe.2012.03.019.

[3] Jianmai Shi, Guoqing Zhang, Jichang Sha, "Optimal production and pricing policy for a closed loop system,” Resources, Conservation and Recycling,vol. 55, Apr. 2011, pp. 639-647, doi:10.1016/j.resconrec.2010.05.016.

[4] Mahdi M, Seyed J S, Saeed M, "Robust optimal dynamic production/pricing policies in a closed-loop system,” Applied Mathematical Modelling, vol. 37, Sep. 2013, pp. 8141-8161, doi:10.106/j.apm.2013.03.008.

[5] Xiang Li, Yong-jian Li, Xiao-qiang Cai, “Collection Pricing Decision in a Remanufacturing System Considering Random Yield and Random Demand,” System Engineering Theory\&Practice, vol. 29, Aug. 2009, pp. 19-27, doi:10.1016/S1874-8651(10)60060-9.

[6] Yuehong Guo, Junhai Ma, "Research on game model and complexity of retailer collecting and selling in closed-loop supply chain," Applied Mathematical Modelling, vol. 37, Apr. 2013, pp. 5047-5058, doi:10.1016/j.apm.2012.09.034.

[7] Yu-yin Yi, "Closed-loop supply chain game models with product remanufacturing,” Systems Engineering-Theory \& Practice, vol.29, Aug. 2009, pp. 28-35.
[8] Scott W, Supriya M, "Competitive strategy in remanufacturing and the impact of take-back laws, ”Journal of Operations Management, vol. 25, Nov. 2007, pp, 1123-1140, doi:10.1016/j.jom.2007.01.014.

[9] Supriya M, Scott W, "Competition in remanufacturing and the effects of government subsidies," International Journal.of Production Economics, vol. 111, Feb. 2008, pp. 287-298, doi:10.1016/j.ijpe.2007.02.042.

[10] Shu-hong Zhang, Jin-long Zhang, Kai-jun Leng, "Pricing strategy and coordination mechanism of remanufacturing closed-loop supply chain based on government incentives,” Computer Integrated Manufacturing Systems, vol. 18, Dec. 2012, pp. 2750-2755.

[11] Ma Wei-min,Zhao Zhang, "Different models of closed-loop supply chain with the government replacement-subsidy," Systems Engineering - Theory \& Practice, vol. 32, Sep. 2012, pp. 1938-1944.

[12] Hammond D, Beullens P, “Closed-loop Supply Chain Network Equilibrium Under Legislation,” European Journal of Operational Research, vol. 183, Dec. 2007, pp. 895-908, doi:10.1016/j.ejor.2006.10.033.

[13] Yenming J. Chen, Jiuh-Biing S, "Environmental regulation pricing strategies for green supply chain management," Transportation Research Part E, vol. 45, Sep. 2009, pp. 667-677, doi:10.1016/j.tre.2009.04.010.

[14] Rui Zhao, Gareth Neighbour, Jiaojie Han, Michael McGuire, Pauline Deutz, "Using game theory to describe strategy selection for environmental risk and carbon emissions reduction in the green supply chain, "Journal of Loss Prevention in the Process Industries, vol. 25, Nov. 2012, pp. 927-936, doi:10.1016/.jlp.2012.05.004.

[15] Sheu J B,"Bargaining Framework for Competitive Green Supply Chains under Governmental Financial Intervention,’Transportation Research Part E, vol. 47, Sep. 2011, pp. 573-592, doi:10.1016/j.tre.2010.12.006.

[16] Jiuh-Biing Sheu, Yenming J. Chen, "Impact of government financial intervention on competition among green supply chains,"International Journal of Production Economics, vol. 138, Jul. 2012, pp. 201-213, doi:10.1016/j.ijpe.2012.03.024. 